Original Research Article

\title{
Protective effect of tadalafil in diabetic nephropathy induced rat model
}

\author{
Abdel Hamid M. Elhawary, Omaima M. Abd Allah*
}

Department of Pharmacology, Faculty of Medicine, Benha University, Benha, Egypt

Received: 24 February 2017 Accepted: 01 March 2017

\section{*Correspondence to:}

Dr. Omaima M. Abd Allah, Email:

omiama_afify@yahoo.com

Copyright: (C) the author(s), publisher and licensee Medip Academy. This is an openaccess article distributed under the terms of the Creative Commons Attribution NonCommercial License, which permits unrestricted noncommercial use, distribution, and reproduction in any medium, provided the original work is properly cited.

\begin{abstract}
Background: Among various mechanisms involved in the pathogenesis of diabetic nephropathy (DN), abnormalities in renal nitric oxide (NO) generation has attracted a lot of attention. Tadalafil, a competitive inhibitor of cyclic guanosine monophosphate (cGMP)-specific phosphodiesterase type 5 commonly used in the treatment of erectile dysfunction was suggested to play a potential prophylactic role for DN. However, this role has not been fully elucidated. The present study was designed to explore the potential beneficial effect of low- dose tadalafil on the progression of diabetic nephropathy in streptozotocin (STZ) induced diabetic rat model.

Methods: After injection of STZ and verifying establishment of diabetes, rats were divided into 4 groups: control, diabetic-control, tadalafil-treated nondiabetic, and tadalafil-treated diabetic groups. Biochemical and hemodynamic parameters affecting the renal function such as blood glucose level, serum level of urea and creatinine, renal blood flow, urine volume, urinary albumin excretion, $\mathrm{Na}+$ and $\mathrm{K}+$ excretion, renal level of nitrite and nitrate, plus renal tissues antioxidant parameters (total antioxidant capacity, superoxide dismutase activity and glutathione content) were detected 8 weeks after administration of tadalafil. Histopathological and electron microscopy examination were performed.
\end{abstract}

Results: Our results demonstrated that tadalafil attenuated the glycemic, renal biochemical, microscopic and ultramicroscopic changes/injuries caused by STZ- induced diabetes. Tadalafil could effectively increase renal blood flow and ameliorate glomerular basement membrane thickening.

Conclusions: From the results it can be concluded that tadalafil protects rats against streptozotocin-induced DN possibly, in part, through its effect on renal nitric oxide level and its antioxidant activity.

Keywords: Diabetic nephropathy, Histopathological changes, Oxidative stress, Rats, Tadalafil

\section{INTRODUCTION}

Diabetes mellitus (DM) is a major global health problem that causes several micro- and macro-vascular complications. Among these is diabetic nephropathy (DN). DN is the main cause of end-stage renal disease and is associated with a high morbidity and mortality. It develops due to a complex interaction between metabolic and haemodynamic pathophysiological factors, which lead to renal damage. In the earliest stage of $\mathrm{DN}$, patient usually presents with an increase in urinary albumin excretion (microalbuminuria) which progress to macroalbuminuria (more than $300 \mathrm{mg}$ in a 24-hour collection) and later renal insufficiency. ${ }^{1}$

Among the various mechanisms involved in the pathogenesis of diabetic nephropathy, abnormalities in renal nitric oxide (NO) generation has attracted a lot of attention. NO is postulated to play a protective role towards ischemic injuries of vascular tissues including renal vascular endothelium, an action mediated via cyclic guanosine monophosphate (cGMP) which initiates renal vascular smooth muscle relaxation. ${ }^{2} \mathrm{NO}$ plays numerous physiological roles in the kidney, including control of renal and glomerular hemodynamics, dilates both the 
afferent and the efferent arteriole; it may augment the glomerular filtration rate (GFR) and influence renal sodium handling along various tubule segments from the thick ascending limb to the distal tubule and the collecting duct. ${ }^{2}$ Therefore, one convenient option for treating the $\mathrm{DN}$-induced enhancement of intraglomerular pressure and the resultant glomerular hypertension is to alter the renal cGMP-NO pathway. ${ }^{3,4}$ It is now obvious that the vascular cGMP-NO pathway can be enhanced by inhibitors of phosphodiesterase type 5 (PDE 5), the enzyme which breakdowns cGMP. ${ }^{5}$ Tadalafil, a highly selective competitive inhibitor of cGMP-specific PDE 5, is commonly used in the treatment of erectile dysfunction. ${ }^{6}$ It has many advantages over the other currently available PDE 5 inhibitors because it is long acting ( up to $36 \mathrm{~h}$ ). Tadalafil is also the only PDE 5 inhibitor whose activity is unaffected by food and has a relatively rapid onset of action (15-17 mins). ${ }^{7}$ Tadalafil has enhanced specificity for PDE-5 as opposed to PDE-6, which may reduce its potential for causing clinical ocular toxicity. ${ }^{8}$ It was found that chronic treatment with tadalafil improved fasting glucose levels and reducing infarct size following ischemia-reperfusion injury in diabetic hearts. ${ }^{9}$ In addition, tadalafil treatment attenuated reactive oxygen species (ROS) generation and preserved the loss of mitochondrial membrane potential in cardiomyocytes in vitro and attenuated myocardial oxidative stress including in vivo lipid peroxidation. ${ }^{10}$ However, the possible role of tadalafil in prevention and treatment of DN has not been fully elucidated. Therefore this study was designed to explore the effects of low-dose tadalafil on the development and progression of nephropathy in streptozotocin (STZ)-induced diabetic rat model (Type I diabetes).

\section{METHODS}

\section{Animals and experimental design}

A total of thirty two Sprague-Dawley adult male rats with initial body weight of 150-180 g were obtained from Helwan farm (Holding Company for Biological Products and Vaccines, VACSERA, Egypt). Experiments were performed after one week of proper acclimatization to the standard conditions $\left[22 \pm 2{ }^{\circ} \mathrm{C} ; 12 \mathrm{~L}: 12 \mathrm{D}\right.$ cycle (lights on at 07:00 hr); and about $60 \%$ humidity] and standard laboratory chow diet containing normal sodium and tap water was provided ad libitum. The experimental protocol was approved by ethical committee (Faculty of medicine, Benha University, Egypt) and the study was conducted in conformity with international ethical guidelines of the care and use of laboratory animals (National Institutes of Health guide for the care and use of Laboratory animals, NIH Publications No. 8523, 1985). Animals were randomly divided into four groups of 8 animals each as followed:

- Group one served as the control group: rats were received single intraperitoneal injection of 0.1 mole citrated buffer at $\mathrm{pH} 4.5$ (vehicle of STZ) and received $1 \mathrm{ml} /$ rat of $0.5 \%$ carboxymethyl-cellulose (CMC) orally for eight weeks (vehicle of tadalafil).

- Group two served as diabetic-control group (model group): rats received single intraperitoneal injection of STZ $(60 \mathrm{mg} / \mathrm{kg})$ and received $1 \mathrm{ml} / \mathrm{rat}$ of $0.5 \%$ carboxymethyl-cellulose (CMC) orally for eight weeks (vehicle of tadalafil).

- Group three served as tadalafil-treated non-diabetic group: rats were received single intraperitoneal injection of 0.1 mole citrated buffer at $\mathrm{pH} 4.5$ (vehicle of STZ) and administered daily oral lowdose of tadalafil $0.45 \mathrm{mg} / \mathrm{kg}$ (equivalent to the lowest adult human dose of $5 \mathrm{mg}$ ) (Lilly Corporation, USA) suspended in $1 \mathrm{ml}$ of $0.5 \% \mathrm{CMC}$ for eight weeks. $^{11}$

- Group four served as tadalafil-treated diabetic group: diabetic rats were administered daily oral tadalafil in a dose of $0.45 \mathrm{mg} / \mathrm{kg}$ suspended in $1 \mathrm{ml}$ of $0.5 \% \mathrm{CMC}$ for eight weeks.

Diabetes was induced in groups two (diabetic-control group) and four (tadalafil-treated diabetic group), by a single intraperitoneal injection of STZ $(60 \mathrm{mg} / \mathrm{kg})$ to overnight fasted rats (STZ powder from Sigma Chemicals Co., USA with creamy white color that was dissolved in cold 0.1 mole citrated buffer at $\mathrm{pH} 4.5) .^{12}$ The STZ-treated animals were allowed to drink $20 \%$ glucose solution for $24 \mathrm{~h}$ to overcome initial druginduced hypoglycemic mortality. After 72 hours, blood samples were collected through the tail vein and blood glucose levels were measured using a glucometer (OneTouch Horizon, Life Scan, Johnson and Johnson, CA, USA). Animals with blood glucose above $250 \mathrm{mg} / \mathrm{dl}$ were used for the study. Afterwards, groups three (tadalafil-treated non-diabetic group) and four (tadalafiltreated diabetic group) were administered daily oral tadalafil while groups one and two were administered a vehicle. At the end of the study period, blood samples were obtained from the tail vein of fasted rats to measure the fasting blood glucose (FBG) level by glucose oxidase method. ${ }^{13}$

Animals were accommodated in metabolic cage for 24 hours for urine collection. Thereafter, rats were anesthetized with pentobarbital $(50 \mathrm{mg} / \mathrm{kg})$ and then were fixed on operating table, the abdominal cavity was opened and the kidneys were exposed. Right renal artery was located and freed. The flow probe was placed on top of the right renal artery for the measurement of renal blood flow (RBF) by the flow meter (Hugo Sachs Elektronik-Harvard apparatus). After measuring RBF, blood samples were collected by cardiac puncture and incubated at $37^{\circ} \mathrm{C}$ until blood clotted and then centrifuged at $3000 \mathrm{rpm}$ for $15 \mathrm{~min}$ to obtain clear sera which stored at $-20^{\circ} \mathrm{C}$ for biochemical analysis. Kidneys were removed; the longitudinal section of the left kidney was excised from each animal for histological examination. The renal cortex of the rest of the kidneys was snap frozen in liquid nitrogen, stored at $-80^{\circ} \mathrm{C}$, and 
subsequently homogenized in cold potassium phosphate buffer $(0.05 \mathrm{M}, \mathrm{pH} 7.4)$ for various biochemical analysis.

\section{Biochemical analysis}

Serum urea and creatinine were measured spectrophotometrically using commercially available kits purchased from Human GmbH (Wiesbaden, Germany). PFP7 Flame photometer (JENWAY, United Kingdom) was used for measurement of urine $\mathrm{Na}^{+}$and $\mathrm{K}^{+}$levels. Cobas ${ }^{\circledR} 111$ analyzer (Roche Diagnostics, Germany) was used for measuring urinary albumin using albumin kit (ALBT2, Tina-quant, Germany). Renal cortex nitric oxide level was measured as total nitrite-nitrate, the stable degradation products of nitric oxide, by reduction of nitrate into nitrite using copperized cadmium, followed by color development with Griess reagent in acidic medium. ${ }^{14}$ Micro plate Reader (Platos R 496) was used for measuring renal tissue glutathione level (GSH) and Fluroskan ascent (2.6 thermo scientific) for measuring total antioxidant capacity (TAC) and superoxide dismutase activity (SOD) in the renal tissues.

\section{Histopathology}

Renal tissue samples were fixed in $10 \%$ neutral buffered formalin, dehydrated in increasing concentrations of ethanol, cleared with xylene and embedded in paraffin. Then $3 \mu \mathrm{m}$ thick sections were cut of each block on glass slides and stained with Periodic Aside-Schiff (PAS) stain to examine the basement membranes and mesangial matrix. For transmission electron microscopy, renal tissue samples were prefixed in $2 \%$ glutaraldehyde in phosphate buffer ( $\mathrm{pH}$ 7.2). The specimens were then post fixed in $1 \%$ phosphate-buffered osmium tetroxide, dehydrated through ethanol and propylene oxide, and embedded in araldite. Semithin sections were stained with azure II and methylene blue. Ultrathin sections of 70-90 nm were obtained from the selected blocks, stained with uranyl acetate and lead citrate for 30 minutes at room temperature and then they were rinsed thoroughly with double filtered distilled water. Finally, the sections were examined under JEOL electron microscope and images were captured by a Gatan imaging system.

\section{Renal morphology analysis}

Analysis of the sections with PAS was performed to compare between the groups. The average mesangial cellularity was achieved by observing 20 glomeruli of each rat and the data was recorded as mean $\pm \mathrm{SD}$, average of (1-2) cell are considered normal while (2-3) cells are considered mildly increased. The mesangial matrix of 20 glomeruli were observed and giving a result of normal matrix (0), mild increase $(+)$, moderately increase $(++)$ and severely increase $(+++)$. The tubules assessment and the abnormal findings were recorded, tubular injury was observed through the present of tubular dilatation and flattening of the tubular epithelial cells. The dilatation of the tubules were observed in all sections by observing five random field at $\mathrm{x} 10$ magnification and a grade of the dilatation was given as normal $(\mathrm{N})$, grade I (GI) which represents the presence of average of $\leq 25 \%$ tubular dilatation, GII which represents the presence of average of $25-50 \%$ tubular dilatation and GIII which represents the presence of average of $50-75 \%$ tubular dilatation.

\section{Statistical analysis}

Results are presented as mean \pm standard deviation (mean \pm SD). Statistical analysis was performed using one-way analysis of variance (ANOVA) to detect significant differences between the group means followed by TukeyKramer multiple comparison test. A $p$ value of $<0.05$ was considered statistically significant. All statistical analyses were performed with GraphPad Prism version 4.03 (GraphPad Software Inc, San Diego, CA, USA).

\section{RESULTS}

\section{Fasting blood glucose}

In diabetic-control group, there was a significant increase $(p<0.05)$ in FBG compared to control group. In comparison to control group, tadalafil treatment did not induce significant changes in FBG in tadalafil-treated non-diabetic group but resulted in significant reduction $(p<0.05)$ in tadalafil-treated diabetic group (Table 1).

Table 1: Effect of tadalafil $(0.45 \mathrm{mg} / \mathrm{kg}$, orally for 8 weeks) on fasting blood glucose, serum urea, and serum creatinine in diabetic and non-diabetic rats.

\begin{tabular}{|llll|}
\hline Groups & $\begin{array}{l}\text { Fasting } \\
\text { blood } \\
\text { glucose } \\
(\mathrm{mg} / \mathrm{dl})\end{array}$ & $\begin{array}{l}\text { Serum } \\
\text { urea } \\
(\mathrm{mg} / \mathrm{dl})\end{array}$ & $\begin{array}{l}\text { Serum } \\
\text { creatinine } \\
(\mathrm{mg} / \mathrm{dl})\end{array}$ \\
\hline Control & $98.2 \pm 14.5$ & $24.4 \pm 3.5$ & $0.88 \pm 0.27$ \\
\hline $\begin{array}{l}\text { Diabetic- } \\
\text { control }\end{array}$ & $347.3 \pm 26.2^{\mathrm{a}}$ & $52.8 \pm 9.6^{\mathrm{a}}$ & $3.23 \pm 0.76^{\mathrm{a}}$ \\
\hline $\begin{array}{l}\text { Tadalafil- } \\
\text { treated non- } \\
\text { diabetic }\end{array}$ & $99.7 \pm 12.8^{\mathrm{b}}$ & $25.3 \pm 4.7^{\mathrm{b}}$ & $0.92 \pm 0.23^{\mathrm{b}}$ \\
\hline $\begin{array}{l}\text { Tadalafil- } \\
\text { treated } \\
\text { diabetic }\end{array}$ & $192.4 \pm 22.3^{\mathrm{abc}}$ & $36.2 \pm 5.8^{\mathrm{abc}}$ & $1.61 \pm 0.43^{\mathrm{abc}}$ \\
\hline
\end{tabular}

Values are expressed as mean \pm SD ( $\mathrm{n}=8$ rats) ${ }^{\mathrm{a}} \mathrm{P}<0.05$ significant difference when compared to control group; ${ }^{\mathrm{b}} \mathrm{P}<0.05$ significant difference when compared to diabetic control group; ${ }^{\mathrm{c}} \mathrm{P}<0.05$ significant difference when compared to tadalafiltreated non diabetic group.

\section{Serum urea and creatinine}

There was statistically significant increase $(\mathrm{p}<0.05)$ in serum urea and creatinine levels in diabetic- control group compared to control group. Treatment with tadalafil resulted in no change in non-diabetic rats and in a significant decrease $(\mathrm{p}<0.05)$ in both serum urea and creatinine levels in diabetic rats (Table 1). 


\section{Renal blood flow}

There was no observed significant difference between control and tadalafil- treated non-diabetic groups. However, there was a statistically significant decrease $(\mathrm{p}<0.05)$ in RBF level in diabetic-control group compared to control rats. Treatment of diabetic rats with tadalafil resulted in a significant increase $(\mathrm{p}<0.05)$ in RBF level compared to diabetic control group (Figure 1).

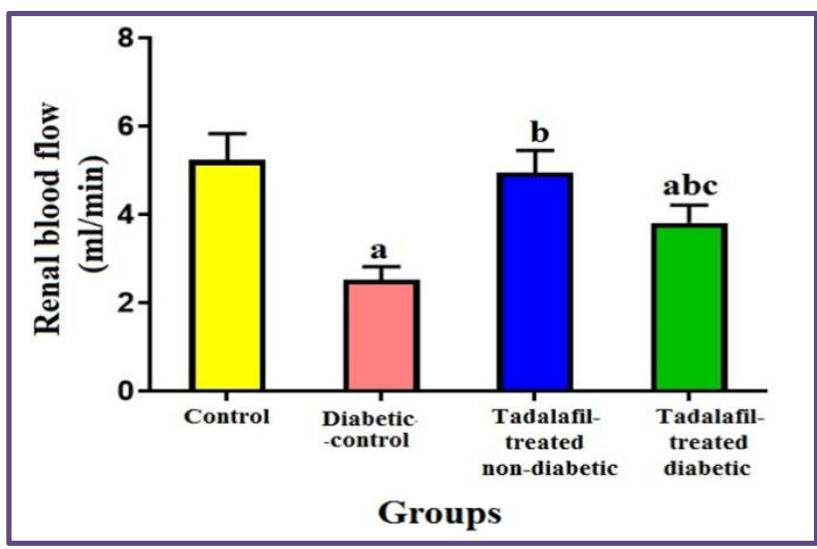

Statistically significant different $(\mathrm{p}<0.05)$ from: $a$ : control, $b$ : diabetic-control group; c: tadalafil-treated non-diabetic group. Data are presented as mean \pm SD.

Figure 1: Renal blood flow in control, diabeticcontrol, tadalafil-treated non-diabetic and tadalafiltreated diabetic groups.

\section{Urine volume}

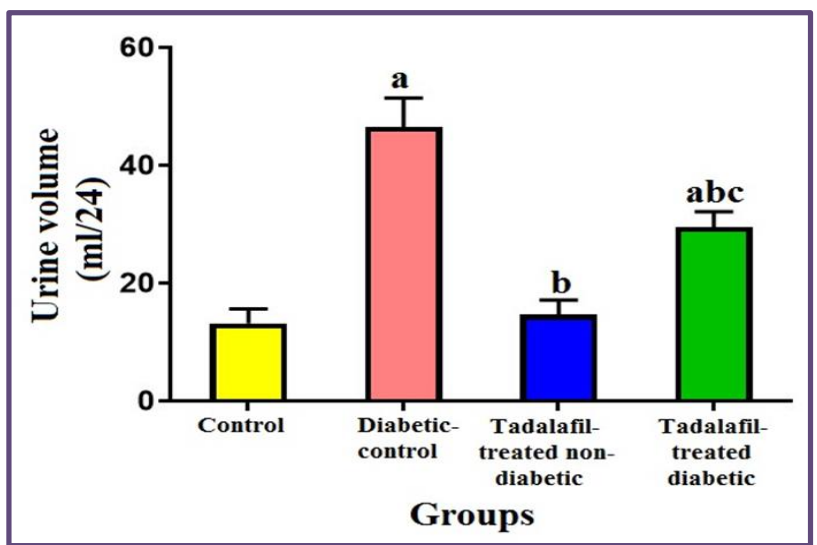

Statistically significant different $(\mathrm{p}<0.05)$ from: $\mathrm{a}$ : control, $\mathrm{b}$ : diabetic-control group; c: tadalafil-treated non-diabetic group. Data are presented as mean \pm SD.

Figure 2: Urine volume in control, diabetic-control, tadalafil-treated non-diabetic and tadalafil-treated diabetic rats.

Urine volume was significantly increased $(\mathrm{p}<0.05)$ in diabetic-control group compared to control group, while treatment of the diabetic rats with tadalafil induced significant increase $(\mathrm{p}<0.05)$ in urine volume compared to control group and significant decrease $(p<0.05)$ in urine volume compared to diabetic-control group despite the fact that treatment with tadalafil in non-diabetic group compared to control did not induce any significant change in urine volume (Figure 2).

\section{Urinary albumin excretion}

No significant difference in urinary albumin excretion was observed between control and tadalafil-treated nondiabetic group. However, in diabetic-control group, there was a significant increase $(\mathrm{p}<0.05)$ in urinary albumin excretion compared to control group. In tadalafil-treated diabetic group, there was also a significant decrease $(\mathrm{p}<0.05)$ in urinary albumin excretion compared to diabetic control group but this decrease was still significantly higher than control or tadalafil-treated nondiabetic group (Table 2).

\section{$\mathrm{Na}^{+}$and $\mathrm{K}^{+}$excretion}

Both $\mathrm{Na}^{+}$and $\mathrm{K}^{+}$excretion were significantly decreased $(p<0.05)$ in diabetic control rat group compared to control rats. Treatment with tadalafil in non-diabetic group did not induce any significant changes in $\mathrm{Na}^{+}$or $\mathrm{K}^{+}$ excretion. However, it resulted in a significant increase ( $\mathrm{p}$ $<0.05)$ in $\mathrm{Na}^{+}$and $\mathrm{K}^{+}$excretion in diabetic rats compared to diabetic control group (Table 2).

Table 2: Effect of tadalafil $(0.45 \mathrm{mg} / \mathrm{kg}$, orally for 8 weeks) on urinary albumin excretion, $\mathrm{Na}+$ and $\mathrm{K}+24$ hour urinary excretion in diabetic and non-diabetic rats.

\begin{tabular}{|c|c|c|c|}
\hline Groups & $\begin{array}{l}\text { Urinary } \\
\text { albumin } \\
\text { (mg/dl) }\end{array}$ & $\begin{array}{l}\mathrm{Na}^{+} \\
\text {excretion } \\
(\mathrm{mmol} / 24 \mathrm{~h})\end{array}$ & $\begin{array}{l}\mathrm{K}^{+} \text {excretion } \\
(\mathrm{mmol} / 24 \mathrm{~h})\end{array}$ \\
\hline Control & $1.8 \pm 0.3$ & $0.98 \pm 0.3$ & $2.48 \pm 0.4$ \\
\hline $\begin{array}{l}\text { Diabetic- } \\
\text { control }\end{array}$ & $14.3 \pm 1.1^{\mathrm{a}}$ & $0.29 \pm 0.1^{\mathrm{a}}$ & $0.94 \pm 0.5^{\mathrm{a}}$ \\
\hline $\begin{array}{l}\text { Tadalafil } \\
\text { treated non } \\
\text { diabetic }\end{array}$ & $1.9 \pm 0.2^{b}$ & $0.96 \pm 0.2^{b}$ & $2.42 \pm 0.5^{b}$ \\
\hline $\begin{array}{l}\text { Tadalafil- } \\
\text { treated } \\
\text { diabetic }\end{array}$ & $6.7 \pm 0.9^{\mathrm{abc}}$ & $0.59 \pm 0.1^{\mathrm{abc}}$ & $1.63 \pm 0.6^{\mathrm{abc}}$ \\
\hline \multicolumn{4}{|c|}{$\begin{array}{l}\text { Values are expressed as mean } \pm \mathrm{SD} \text { ( } \mathrm{n}=8 \text { rats) }{ }^{\mathrm{a}} \mathrm{p}<0.05 \\
\text { significant difference when compared to control group. }{ }^{\mathrm{b}} \mathrm{p}<0.05 \\
\text { significant difference when compared to diabetic-control group. } \\
{ }^{\mathrm{c} p}<0.05 \text { significant difference when compared to tadalafil- } \\
\text { treated non-diabetic group. }\end{array}$} \\
\hline
\end{tabular}

\section{Renal tissue nitrite and nitrate Levels}

The renal tissue concentrations of nitrite and nitrate were significantly decreased $(\mathrm{p}<0.05)$ in diabetic control group compared to control. Treatment with tadalafil resulted in significant increase $(p<0.05)$ in nitrite-nitrate levels compared to diabetic-control group (Table 1). In tadalafil-treated non-diabetic group, nitrite-nitrate levels were insignificantly increased $(\mathrm{p}>0.05)$ compared to control group (Figure 3). 


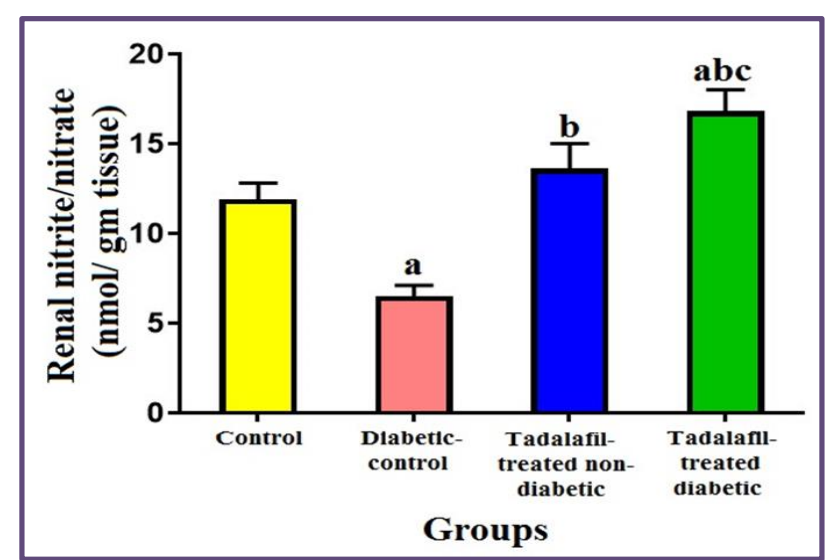

Alphabet describes statistically significant different $(\mathrm{p}<0.05)$ from: a: control, b: diabetic-control group; c: tadalafil-treated non-diabetic group. Data are presented as mean \pm SD.

Figure 3: Renal tissue nitrite and nitrate in control, diabetic-control, tadalafil-treated non-diabetic and tadalafil-treated diabetic groups.

\section{Antioxidant activity}

TAC, SOD activity and GSH level in renal tissues were all statistically decreased $(\mathrm{p}<0.05)$ in diabetic-control group compared to control. Treatment with tadalafil induced a significant increase $(\mathrm{p}<0.05)$ in the levels of these markers when compared to diabetic-control group. These markers were all higher and statistically significant $(\mathrm{p}<0.05)$ in tadalafil-treated diabetic rats when compared to diabetic-control group (Table 3).

Table 3: Effect of tadalafil $(0.45 \mathrm{mg} / \mathrm{kg}$, orally for 8 weeks) on total antioxidant capacity (TAC), superoxide dismutase activity (SOD) and glutathione concentration (GSH) in diabetic and non-diabetic rats.

\begin{tabular}{|llll|}
\hline Groups & $\begin{array}{l}\text { TAC } \\
\text { (nmol/mg } \\
\text { protein) }\end{array}$ & $\begin{array}{l}\text { SOD } \\
(\mathrm{nmol} / \mathrm{mg} \\
\text { protein) }\end{array}$ & $\begin{array}{l}\text { GSH } \\
\text { (nmol/mg } \\
\text { protein) }\end{array}$ \\
\hline Control & $66.4 \pm 10.2$ & $44.9 \pm 2.6$ & $21.3 \pm 1.1$ \\
\hline $\begin{array}{l}\text { Diabetic- } \\
\text { control }\end{array}$ & $28.6 \pm 2.9^{\mathrm{a}}$ & $19.4 \pm 1.5^{\mathrm{a}}$ & $9.7 \pm 0.8^{\mathrm{a}}$ \\
\hline $\begin{array}{l}\text { Tadalafil- } \\
\text { treated non- } \\
\text { diabetic }\end{array}$ & $68.3 \pm 11.2^{\mathrm{b}}$ & $46.2 \pm 2.7^{\mathrm{b}}$ & $22.6 \pm 1.2^{\mathrm{b}}$ \\
\hline $\begin{array}{l}\text { Tadalafil- } \\
\text { treated } \\
\text { diabetic }\end{array}$ & $47.5 \pm 3.6^{\mathrm{abc}}$ & $36.3 \pm 2.1^{\mathrm{abc}}$ & $15.8 \pm 1.2^{\mathrm{abc}}$ \\
\hline
\end{tabular}

Values are expressed as mean \pm SD ( $n=8$ rats); ${ }^{\mathrm{a}} \mathrm{P}<0.05$ significant difference when compared to control group. ${ }^{\mathrm{b}} \mathrm{P}<0.05$ significant difference when compared to diabetic-control group. ${ }^{\mathrm{c}} \mathrm{P}<0.05$ significant difference when compared tadalafil treated non-diabetic group.

\section{Histopathology}

The normal control rats showed normal kidney histology with normal mesangial cellularity (average 1-2 cells) and normal matrix (0) (Figure 4A). The tubules were normal (N) and fine protein droplets were observed in the proximal tubules (Figure 4E). The diabetic-control group showed some architectural damage with increased mesangial cellularity (average $2-4$ cells) and a moderate increase in the mesangial matrix (++) (Figure 4B). The tubules showed acute tubular injury with mild tubular dilatation and flattening of the lining epithelial cells (GII). Foamy cells were seen in the convoluted tubules of some diabetic rat kidney (Figure 4F).
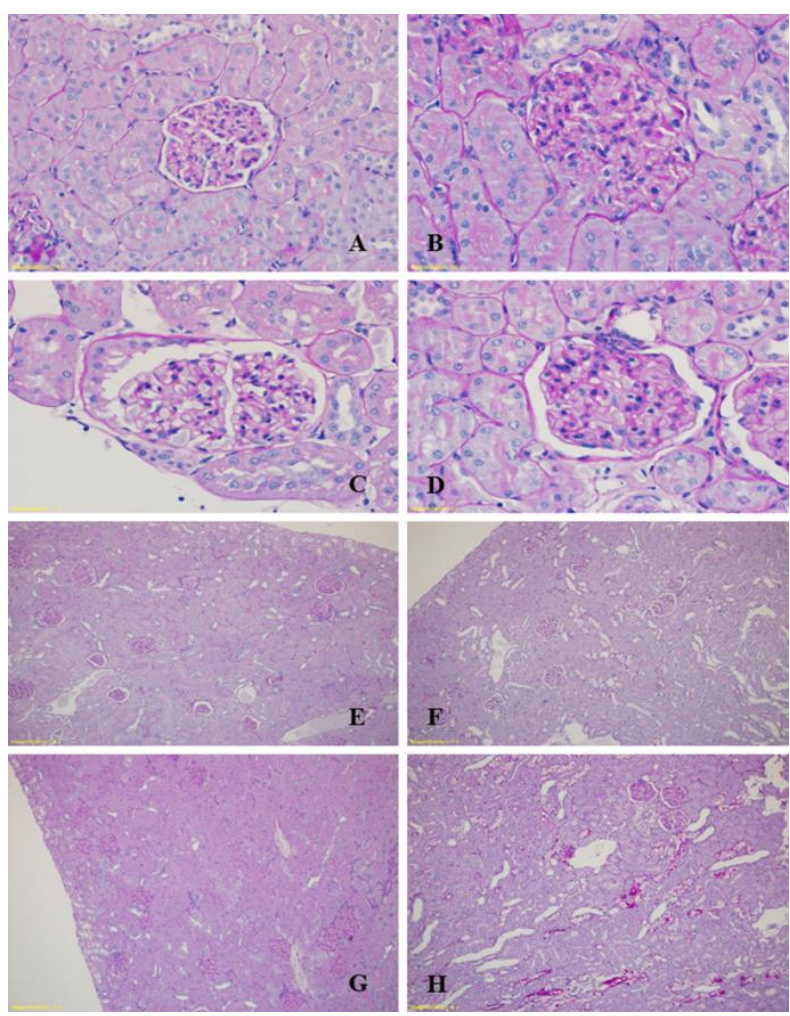

Figure 4: Representative light microscopic photographs of renal sections of glomerulus (A-D) and tubules (E-H) from control $(A, E)$, diabetic-control $(B$, F), tadalafil-treated non-diabetic $(C, G)$ and tadalafiltreated diabetic rats $(D, H)$. Staining was carried out with periodic acid-Schiff stain. (A X 400), (B,C,D X 600), (E,F,G,H X 100).

Tadalafil-treated non-diabetic rats showed normal mesangial cellularity, matrix and tubules (Figure 4C). However, there were mild increase in protein droplets size and amount in the tubular cells (Figure 4G) in comparison to the above groups. Tadalafil-treated diabetic rats showed an average normal mesangial cellularity (average 1-2) cells and matrix $(0$ to + ) (Figure 4D) but there was a mild tubular dilatation (GI) with high number of tubules presenting foamy cells that showed high affinity for PAS stain (Figure $4 \mathrm{H}$ ). Fine protein droplets were also seen in the tubular cells cytoplasm. 
The mesangium and podocyte foot processes were normal in control rats while diabetic-control in general had increased mesangial matrix and mild effacement in the foot processes. Tadalafil treatment resulted in the appearance of normal mesangial matrix and normal non effaced foot processes (Figure 5).

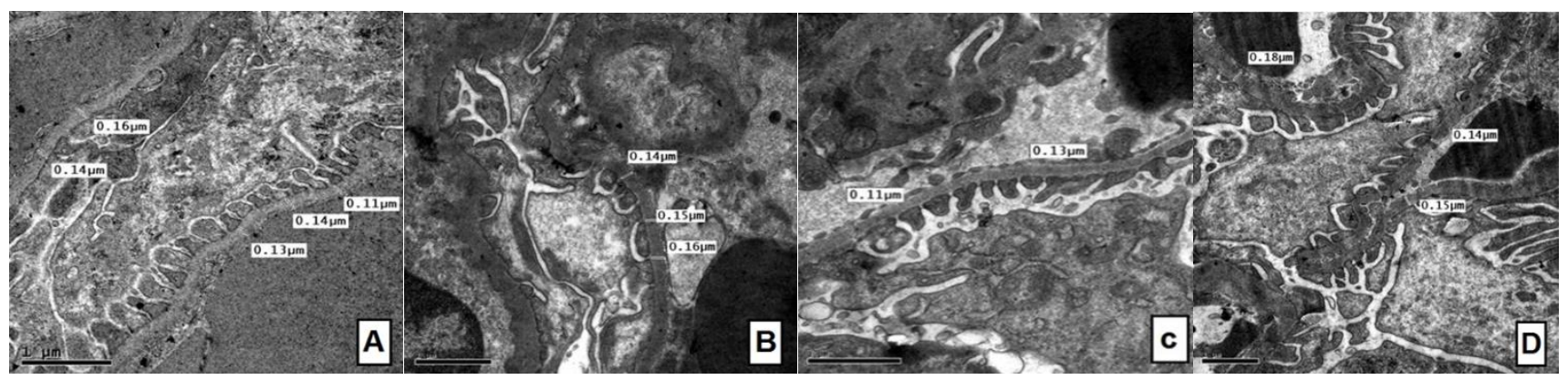

Figure 5: Representative electron microscopic photographs of renal sections of mesangium, glomerular basement membrane and podocytes from control (A), diabetic-control (B), tadalafil-treated non-diabetic (C) and tadalafiltreated diabetic rats (D) (Magnification: 20,000x).

The mean glomeruli basement membrane thickness of control group, diabetic-control, tadalafil- treated non diabetic group and tadalafil-treated diabetic group were $144.3 \pm 15 \mathrm{~nm}, 195.8 \pm 26 \mathrm{~nm}, 146.2 \pm 18 \mathrm{~nm}$ and $165.7 \pm 21$ $\mathrm{nm}$ respectively. The difference in these means were statistically significant $(\mathrm{p}<0.05)$.

\section{DISCUSSION}

The effect of tadalafil on different organs was investigated in several studies, Sesti et al demonstrated the cardio protective effect of tadalafil in a model of experimental myocardial infarction. ${ }^{15}$ Sawamura et al suggested that tadalafil is effective in the treatment of the late phase of pulmonary arterial hypertension through relaxation of pulmonary arteries in lungs. ${ }^{16}$ In addition, the acute effect of tadalafil as a reno protective agent was demonstrated in experimental renal ischemia/reperfusion injury model in the rat. ${ }^{17}$ More recently, Wang et al demonstrated that tadalafil is effective and safe for the treatment of diabetic neuropathy as it increases regional blood flow in the sciatic nerve tissue and improves peripheral nerve function in type II diabetic mice. ${ }^{18}$

In the present study, chronic low dose tadalafil treatment attenuated the progression of DN in STZ- induced diabetic rats. Tadalafil treatment lead to a significant reduction in FBG level compared to non-tadalafil treated diabetic rats. It has been shown that chronic but not acute inhibition of phosphodiesterase-5 may enhance insulin action and improve energy balance in vivo. ${ }^{19}$ Varma et al reported that chronic treatment with tadalafil improved fasting glucose levels and reduced infarct size following ischemia-reperfusion injury in diabetic rat hearts. Although the mechanism is not fully clear but it has been shown that in STZ-induced diabetes and due to hyperglycemia the renal autoregulation is impaired in the early stage leading to a rapid and progressive increase in $\mathrm{RBF}$ which is significantly dependent upon an increase in NO activity. During progression of diabetes, a gradual increase in angiotensin II resulting in vasoconstriction, which preferentially constricts renal efferent arterioles rather than afferent arterioles. ${ }^{20}$ The sustained vasoconstriction of renal arterioles leads to decreased $\mathrm{RBF}$ and GFR in diabetes with a concomitant reduction in NO activity. The diabetes-induced reduction in NO activity could be due to a defect in synthesis or quenching through the production of superoxide radicals and advanced glycosylation end products. ${ }^{20}$ In the context of renal function an increase in NO/cGMP activity would cause renal vasodilation.

Through inhibition of the phosphodiesterase enzyme, which destroys nitric oxide, tadalafil increases nitric oxide which in turn causes renal vasodilatation, increases renal medullary blood flow, and mediates the removal of free oxygen radicals. ${ }^{21}$ In accordance with the previous report, results of the present study verified that tadalafil administration significantly increased renal tissue NO level in diabetic rats which could decrease renal vascular resistance resulting in increases in renal blood flow. Although there is some controversy, most reports suggest higher levels of NO production early in diabetes but reduced levels in progressive $\mathrm{DN}^{2}$

Our results showed that tadalafil reduced albuminuria and improved the renal status in diabetic nephropathy. It appears that this property is only evident when kidney function is impaired, since tadalafil produced no effect on the renal function of non-diabetic rats.

In the early stages of diabetes there is usually an increase in thromboxane production, renin secretion and urinary albumin excretion. In addition, and due to glucose-linked sodium transport, the increase in tubular glucose causes an increase in the fractional proximal sodium reabsorption. These effects can be corrected via restoration of glycemic control. ${ }^{22}$ Tadalafil almost completely ameliorated these effects possibly via restoration of glycemic control. Tadalafil has been shown to have renoprotective effects against renal ischemia/reperfusion injuries, attenuating the renal 
tubular damage, decreasing apoptosis and suppressing the increase in the blood urea nitrogen and creatinine. ${ }^{23}$ In addition, Ozbek et al showed that acute administration of tadalafil induced significant lowering of serum creatinine and blood urea nitrogen (BUN) values and also decreased serum and renal tissue malondialdehyde (MDA) levels, thus tadalafil protected rat kidney against contrastinduced nephropathy. ${ }^{24}$

The hyperglycemia associated with diabetes can cause cellular changes in glomerular basement membrane and connective tissues supporting the capillary loops leading to glomerulosclerosis. ${ }^{25}$ The histopathological findings validate these findings. Tadalafil attenuated to some extent these changes. The important finding of this work is the effect of tadalafil on the ultramicroscopic changes in the kidney architecture. The characteristic alterations of the diabetic nephropathy appeared in the form of thickening of glomerular basement membrane and effacement of podocytes. Treatment of diabetic rats with tadalafil protected the kidneys from such alterations. One possible mechanism for this attenuation is the effect of tadalafil on oxidative and inflammatory reactions occurring in diabetes.

Oxidative stress mediated by hyperglycemia-induced generation of reactive oxygen species (ROS) plays a pivotal role in the development and progression of diabetic nephropathy. ${ }^{26}$ The diabetic vessels from animal models and endothelial derived cells in cell culture models under hyperglycemic conditions exhibit high levels of ROS associated with decreased levels of endothelial $\mathrm{NO}^{27}$ In this work tadalafil significantly increased the antioxidant activity of SOD, GSH level and TAC when administered to STZ- induced diabetic rats. This mechanism might be the cause for the observed histopathologic attenuation of glomerular hypertrophy, reduced glomerular extracellular matrix expansion and decreased glomerular sclerosis seen in tadalafil treated group when compared to diabetic- control group. In accordance to our findings, Serarslan et al found that tadalafil reduced the spinal cord injury by increasing tissue/serum levels of nitric oxide and serum activity of SOD in rats. ${ }^{28}$ In addition; Chen et al reported that tadalafil decreased MDA levels in the cavernous tissues of rats. ${ }^{29}$

Furthermore, it has been found that tadalafil inhibits the production of lipid peroxidation via inhibition of nicotinamide adenine dinucleotide phosphate (NADPH) oxidase activity which in turn reduces superoxide anion formation. ${ }^{27}$ The results of Koka et al clearly signify the potential antioxidant-like role of chronic tadalafil treatment in diabetes as tadalafil treatment attenuated the oxidized glutathione (GSSG)/ reduced glutathione (GSH) ratio in the serum of diabetic mice. ${ }^{30}$ Recently, Sheweita et al showed that tadalafil reduced malondialdyhyde (MDA) level and increased the activity of antioxidant enzymes in liver tissue of rats. ${ }^{31}$

\section{CONCLUSION}

In conclusion, low dose of tadalafil attenuated the glycemic and renal biochemical, microscopic and ultramicroscopic changes/injuries caused by STZinduced diabetes. Tadalafil could effectively increase renal blood flow and ameliorate glomerular basement membrane thickening. These results further support that tadalafil protects rats against streptozotocin-induced DN possibly, in part, through its effect on renal nitric oxide level and its antioxidant activity.

Funding: No funding sources Conflict of interest: None declared

Ethical approval: The study was approved by the Institutional Ethics Committee

\section{REFERENCES}

1. Arora MK, Singh UK. Molecular mechanisms in the pathogenesis of diabetic nephropathy: an update. Vascul Pharmacol. 2013;58(4):259-71.

2. Dellamea BS, Leitão CB, Friedman R, Canani LH. Nitric oxide system and diabetic nephropathy. Diabetol Metab Syndr. 2014;12,6(1):17.

3. Forbes JM, Fukami K, Cooper ME. Diabetic nephropathy: where hemodynamics meets metabolism. Exp Clin Endocrinol Diabetes. 2007;115:69-84.

4. Giunti S, Barit D, Cooper ME. Mechanisms of diabetic nephropathy: role of hypertension. Hypertension. 2006;48:519-26.

5. Yan C, Kim D, Aizawa T, Berk BC. Functional interplay between angiotensin II and nitric oxide: cyclic GMP as a key mediator. Arterioscler Thromb Vasc Biol. 2003;23:26-36.

6. Daugan A, Grondin P, Ruault C, Le Monnier de Gouville AC, Coste $\mathrm{H}$, et al. The discovery of tadalafil: a novel and highly selective PDE5 inhibitor: 1:5,6,11,11a-tetrahydro-1H-imidazo[1',5':1,6]pyrido [3,4-b]indole-1,3(2H)-dione analogues. J Med Chem. 2003;46:4525-32.

7. Wright PJ. Comparison of phosphodiesterase type 5 (PDE5) inhibitors. Int J Clin Pract. 2006;60(8):96775.

8. Gresser U, Gleiter $\mathrm{CH}$. Erectile dysfunction: comparison of efficacy and side effects of the PDE-5 inhibitors sildenafil, vardenafil and tadalafil-review of the literature. Eur J Med Res. 2002;7(10):435-46.

9. Varma A, Das A, Hoke NN, Durrant DE, Salloum FN, Kukreja RC. Anti-inflammatory and cardioprotective effects of tadalafil in diabetic mice. PLoS One. 2012;7(9):e45243.

10. Koka S, Das A, Salloum FN, Kukreja RC. Phosphodiesterase-5 inhibitor tadalafil attenuates oxidative stress and protects against myocardial ischemia/reperfusion injury in type 2 diabetic mice. Free Radic Biol Med. 2013;60:80-8.

11. Paget GE, Barnes JM. Toxicity tests in evaluation of drug activities pharmacometries (Laurence, DR and 
Bacharach AL eds) Academic Press, London and New York, 1964.

12. Patterson E, Marques TM, O’Sullivan O, Fitzgerald P, Fitzgerald GF, Cotter PD et al. Streptozotocininduced type-1-diabetes disease onset in SpragueDawley rats is associated with an altered intestinal microbiota composition and decreased diversity. Microbiol. 2015;161:182-93.

13. Tinder P. Determination of blood glucose using an oxidase-peroxidase system with a non-carcinogenic chromogen. J Clin Pathol. 1969;22(2):158-61.

14. Sastry KV, Moudgal RP, Mohan J, Tyagi JS, Rao GS. Spectrophotometric determination of serum nitrite and nitrate by copper-cadmium alloy. Anal Biochem. 2002;1,306(1):79-82.

15. Sesti C, Florio V, Johnson EG, Kloner RA. The phosphodiesterase-5 inhibitor tadalafil reduces myocardial infarct size. Int $\mathbf{J}$ Impot Res. 2007;19(1):55-61.

16. Sawamura F, Kato M, Fujita $K$, Nakazawa $T$, Beardsworth A. Tadalafil, a long-acting inhibitor of PDE5, improves pulmonary hemodynamics and survival rate of monocrotaline-induced pulmonary artery hypertension in rats. $\mathrm{J}$ Pharmacol Sci. 2009;111(3):235-43.

17. Lux A, Pokreisz P, Swinnen M, Caluwe E, Gillijns H, Szelid Z, et al. Concomitant phosphodiesterase 5 inhibition enhances myocardial protection by inhaled nitric oxide in ischemia-reperfusion injury. J Pharmacol Exp Ther. 2016;356(2):284-92.

18. Wang L, Chopp M, Szalad A, Lu X, Jia L, Lu M, et al. Tadalafil promotes the recovery of peripheral neuropathy in type ii diabetic mice. Plos One. 2016;11(7):e0159665.

19. Bell TD, DiBona GF, Wang Y, Brands MW. Mechanisms for renal blood flow control early in diabetes as revealed by chronic flow measurement and transfer function analysis. J Am Soc Nephrol. 2006;17(8):2184-92.

20. Arima $S$, Ito $S$. The mechanisms underlying altered vascular resistance of glomerular afferent and efferent arterioles in diabetic nephropathy. Nephrol Dial Transplant. 2003;18:1966-9.

21. Morcos SK. Can selective inhibitors of cyclic guanosine monophosphate (cGMP)-specific phosphadiesterase type 5 (PDE 5) offer protection against contrast induced nephropathy? Quant Imaging Med Surg. 2014;4(4):214-5.

22. De Nicola L, Gabbai FB, Liberti ME, Sagliocca A, Conte G, Minutolo R. Sodium/glucose cotransporter 2 inhibitors and prevention of diabetic nephropathy: targeting the renal tubule in diabetes. Am J Kidney Dis. 2014;64(1):16-24.

23. Gasanov F, Aytac B, Vuruskan H. The effects of tadalafil on renal ischemia reperfusion injury: an experimental study. Bosnian J Basic Med Sci. 2011;11(3):158-162.

24. Ozbek K, Ceyhan K, Koc F, Sogut E, Altunkas F, Karayakali M, et al. The protective effect of single dose tadalafil in contrast-induced nephropathy: an experimental study. Anatol J Cardiol. 2015;15(4):306-10.

25. Arora MK, Singh UK. Oxidative stress: meeting multiple targets in pathogenesis of diabetic nephropathy. Curr Drug Targets. 2014;15(5):531-8.

26. Giacco F, Brownlee M. Oxidative stress and diabetic complications. Circu Res. 2010;107:1058-70.

27. Ding H, Aljofan M, Triggle CR. Oxidative stress and increased eNOS and NADPH oxidase expression in mouse microvessel endothelial cells. J Cell Physiol. 2007;212:682-9.

28. Serarslan Y, Yonden Z, Ozgiray E, Oktar S, Guven EO, Sogut S, et al. Protective effects of tadalafil on experimental spinal cord injury in rats, J. Clin. Neurosci. 2010;17:349-52.

29. Chen Y, Li XX, Lin HC, Qiu XF, Gao J, Dai YT, et al. The effects of long-term administration of tadalafil on STZ-induced diabetic rats with erectile dysfunction via a local antioxidative mechanism, Asian J. Androl. 2012;14:616-20.

30. Koka S, Xi L, Kukreja RC. Chronic treatment with long acting phosphodiesterase-5 inhibitor tadalafil alters proteomic changes associated with cytoskeletal rearrangement and redox regulation in Type II diabetic hearts. Basic Res Cardiol. 2012;107:249.

31. Sheweita S, Salamaa B, Hassanb M. Erectile dysfunction drugs and oxidative stress in the liver of male rats. Toxicology Reports. 2015;2:933-8.

Cite this article as: Elhawary AHM, Abd Allah OM. Protective effect of tadalafil in diabetic nephropathy induced rat model. Int J Basic Clin Pharmacol 2017;6:710-17. 